\title{
Meningkatkan Kemampuan Koneksi Matematik Siswa SMP dengan Menggunakan Pendekatan Metaphorical Thinking Berbantuan Software Geogebra
}

\section{Improving Mathematical Connection Capabilities of Middle School Students by Using the Metaphorical Thinking Approach Using Geogebra Software}

\author{
Martin Bernard ${ }^{1}$, Eka Senjayawati ${ }^{2}$ \\ ${ }^{1,2}$ Institut Keguruan dan Ilmu Pendidikan Siliwangi. \\ Jalan Terusan Jendral Sudirman Cimahi \\ *Korespondensi Penulis. E-mail: ${ }^{1}$ pamartin23rnard@gmail.com, ${ }^{2}$ senja_eka@yahoo.co.id
}

\begin{abstract}
Abstrak
Penelitian ini dilatarbelakangi karena masih rendahnya kemampuan koneksi matematik siswa, dengan tujuan penelitian adalah untuk menelaah pencapaian dan peningkatan kemampuan koneksi siswa SMP melalui pembelajaran menggunakan pendekatan metaphorical thinking berbantuan software Geogebra. Metode pada penelitian ini adalah metode eksperimen dengan dua kelompok yaitu kelas eksperimen dan kelas kontrol, desain penelitian berupa pretest, postest, dan uji gain ternormalisasi. Instrumen tes penelitian terdiri dari 5 soal tes kemampuan koneksi matematik berbentuk uraian. Populasi penelitian ini adalah seluruh siswa SMP di Kabupaten Bandung Barat, sedangkan sampelnya adalah SMP Krida Utama Padalarang. Sampel kelas VIII diambil secara acak kelas dari 12 kelas, diperoleh kelas VIII D sebagai kelas ekperimen, dan kelas VIII C sebagai kelas kontrol. Kelas Eksperimen memperoleh pembelajaran dengan pendekatan metaphorical thinking berbantuan software Geogebra, dan kelas kontrol memperoleh pembelajaran biasa. Data hasil penelitian diperoleh dari hasil pretes, postes, dan uji gain ternormalisasi, yang diolah melalui uji uji normalitas, dan uji Mann-Whitney. Hasil penelitian menunjukan bahwa pencapaian dan peningkatan kemampuan koneksi matematik antasa siswa yang memperoleh pembelajaran dengan pendekatan methaporical thinking berbantuan software Geogebra lebih baik dengan siswa yang memperoleh pembelajaran biasa.
\end{abstract}

Keyword : Pendekatan Metaphorical Thinking, Koneksi Matematik, Software Geogebra

\begin{abstract}
This research is motivated because of the low mathematical connection ability of students, with the aim of the study is to examine and improve the access speed of junior high school students through learning using the Geogebra software-assisted metaphor thinking approach. The method in this study is the experimental method with two groups, namely the experimental class and the control class, the research design in the form of pretest, posttest, and normalized gain test. The research test instrument consists of 5 test questions on the ability of mathematical connections to form a description. The population of this study were all junior high school students in West Bandung Regency, while the sample was Krida Utama Padalarang Middle School. The sample of class VIII was obtained directly from the second grade class, grade VIII was obtained as the experimental class, and class VIII C was the control class. Classroom Experiment learning with a metaphorical thinking approach aided by Geogebra software, and ordinary learning control classes. The research data was obtained from the results of pretest, posttest, and normalized gain test, which
\end{abstract}

DOI : https://dx.doi.org/10.26486/jm.v3i2.558

W : http://ejurnal.mercubuana-yogya.ac.id/index.php/mercumatika

E : mercumatika@mercubuana-yogya.ac.id 
were processed through the normality test, and Mann-Whitney test. The results of the study showed that connecting and connecting students and students who used the Geogebra software-assisted method of metabolic thinking was better with students who read ordinary learning.

Keyword: Patterned Metaphors, Mathematical Connections, Geogebra Software

\section{PENDAHULUAN}

Dalam standar standar isi untuk satuan pendidikan dasar dan menengah standar kompetensi dan kompetensi dasar SMP/MTs menurut Kementrian Pendidikan Nasional (2006:14) pemerintah menetapkan tujuan pembelajaran matematika sebagai berikut:

1. Memahami konsep matematika, menjelaskan keterkaitan antar konsep dan mengaplikasikan konsep atau algoritma, secara luwes, akurat, efisien, dan tepat dalam pemecahan masalah.

2. Menggunakan penalaran pada pola dan sifat, melakukan manipulasi matematika dalam membuat generalisasi, menyusun bukti, atau menjelaskan gagasan dan pernyataan matematika.

3. Memecahkan masalah yang meliputi kemampuan memahami masalah, merancang model matematika, menyelesaikan model dan menafsirkan solusi yang diperoleh.

4. Mengkomunikasikan gagasan dengan simbol, tabel, diagram, atau media lain untuk memperjelas keadaan atau masalah.

5. Memiliki sikap menghargai kegunaan matematika dalam kehidupan, yaitu memiliki rasa ingin tahu, perhatian, dan minat dalam mempelajari matematika, serta sikap ulet dan percaya diri dalam pemecahan masalah.

Dalam tujuan pendidikan matematika yang dikutip dari KTSP (Anita, 2014:126), "Siswa memahami konsep matematika, menjelaskan keterkaitan antara konsep dan mengaplikasikan konsep atau algoritma secara luwes, akurat, efisien dan tepat dalam menyelesaikan masalah". Dalam keterkaitan konsep dan mengaplikasikannya dibutuhkan sebuah koneksi agar setiap konsep dapat terhubung. Hal ini menunjukkan bahwa tahap awal kemampuan yang harus dikuasai siswa adalah kemampuan mengkoneksikan konsep secara matematis yang pada akhirnya kemampuan koneksi matematis ini menjadi prasyarat siswa dapat menguasai kemampuan-kemampuan lain yang lebih tinggi.

Sejalan dengan itu, National Council of Teachers of Mathematics (NCTM) (Rohati, 2015:28) menetapkan lima standar kemampuan matematis yang harus dimiliki oleh siswa, "(1) kemampuan pemecahan masalah, (2) kemampuan komunikasi, (3) kemampuan koneksi, (4) kemampuan penalaran, dan (5) kemampuan representasi”.

Berdasarkan uraian di atas, kemampuan koneksi matematis merupakan salah satu dari lima standar kemampuan matematis yang harus dimiliki oleh siswa. Namun, kemampuan koneksi matematis siswa sekolah menengah di Indonesia masih tergolong rendah. Hal ini dapat dilihat dari prestasi Indonesia pada Programme for International Student Assessment (PISA) yang dilakukan oleh OECD (Organisation for Economic Co-operation and Development). Hasil penelitian PISA (Programme for International Student Assesment) tahun 2012 (Gurria, 2014:19) yang menyatakan bahwa prestasi siswa Indonesia pada matematika berada pada peringkat 64 dari 65 negara peserta studi dengan skor rata-rata 375 , jauh dibawah rata-rata yaitu 494. Terlebih lagi kemampuan siswa Indonesia menyelesaikan soal level 5-6 hanya 0,3 sangat jauh dari rata-rata 12,6.

Hal ini dapat dilihat pula dari penelitian yang dilakukan oleh Danaryanti, A. dan Dara (2016:8) yang meneliti kemampuan koneksi matematik pada kelas VIII SMP yang menghasilkan nilai pencapaian rata-rata kemampuan koneksi matematik siswa SMP hanya 63.3\%. Begitupun penelitian yang dilakukan oleh Saminanto( 2015:267) juga menunjukkan bahwa rata-rata kemampuan koneksi matematis siswa sekolah menengah masih rendah, yakni hanya berada pada nilai $34 \%$,sehingga dapat disimpulkan kemampuan koneksi matematikanya belum dalam kategori baik.

Untuk tercapainya kemampuan koneksi dalam siswa harus lebih ditekankan lagi dalam penyelesaian konsep menghubungkan ide matematik dan konsep kehidupan sehari-hari. Dalam mengarahkan siswa agar dapat menyelesaikan konsep menghubungkan ide matematik dan konsep kehidupan sehari-hari, guru dapat mengarahkan siswa seperti mencari konsep, menemukan konsep, dan mengaplikasikan konsep dalam menyelesaikan masalah dalam soal. Carreira (Afrilianto, 
2012:194) mengemukakan, "Konsep berfikir yang menekankan pada kemampuan menghubungkan ide matematika dan fenomena yang ada diantaranya adalah methaporical thinking".

Sunito (2013:60) mengemukakan, "Pendekatan metaphorical thinking merupakan suatu pendekatan pembelajaran yang menggunakan metafora-metafora untuk menjelaskan suatu konsep". Metafora yang digunakan pada pendekatan ini merupakan proses pemindahan arti dan asosiasi baru dari satu objek atau gagasan yang abstrak ke objek atau gagasan yang lain yang sudah lebih dikenal. Melalui proses bermetafora siswa dilatih untuk mengkoneksikan hubungan-hubungan antara pengetahuan (konsep) yang telah dipelajari sebelumnya dengan pengetahuan (konsep) yang akan dipelajarinya serta siswa dilatih untuk mengkoneksikan konsep matematika dengan hal nyata yang ada di kehidupan sehari-hari. Hal ini sesuai dengan kemampuan koneksi matematis yang ingin dibangun yaitu memahami hubungan antar topik matematika dan menerapkan matematika dalam bidang lain atau dalam kehidupan sehari-hari.

Rendahnya kemampuan koneksi matematis siswa disebabkan oleh faktor kurang terlatihnya siswa untuk menghadapi permasalahan dunia nyata padahal mereka sering menemukannya di kehidupan sehari-hari. Dengan penerapan pendekatan pembelajaran metaphorical thinking di dalam kelas, siswa dapat merasakan langsung belajar matematika sambil memecahkan permasalahan yang berkaitan dengan kehidupan sehari-hari. Mereka menjadi lebih merasakan manfaatnya belajar matematika.

Seiring dengan berkembangnya teknologi, bidang matematika pun mengalami kemajuan. (Ace, 2007:91) menjelaskan, "Kebutuhan untuk memanfaatkan teknologi itu mula-mula dipengaruhi oleh fakta-fakta yang terjadi di komunitas luar sekolah (bisnis, pemerintahan, dan masyarakat umum) yang sudah lazim menggunakan teknologi dalam aktivitas berkomunikasi, mencari informasi, dan aktivitas komersial". Perkembangan teknologi dalam bidang pendidikan adalah dengan adanya software matematika yang dapat digunakan untuk menunjang pembelajaran, sebab dengan menggunakan TIK siswa dapat membantu siswa memberikan kesimpulan (Chotimah, Bernard, \& Wulandari, 2018:2) selain itu pmebelajaran matematika menciptakan siswa lebih menyenangkan dan memunculkan ide (Bernard, 2015:200). Salah satu software matematika yang dapat digunakan adalah software Geogebra. Geogebra adalah software matematika dinamis yang dapat digunakan sebagai alat bantu dalam pembelajaran matematika. Menurut Fazar (2015:31), "Software ini dikembangkan untuk proses belajar mengajar matematika di sekolah oleh Markus Hohenwarter di Universitas Florida Atlantic". Dan software ini memebantu untuk memecahkan masalah dalam bidang geometri (Senjayawati \& Bernard, 2018:16; Anggun Badu Kusuma\& Astri Utami,2017).

Dengan menggunakan pendekatan methaphorical thinking dan berbantuan software Geogebra diharapkan selama proses pembelajaran siswa menjadi bermakna dan dapat meningkatkan kemampuan koneksi matematiknya.

\section{METODE}

Metode yang digunakan dalam penelitian ini adalah metode eksperimen karena adanya manipulasi perlakuan, kelas yang satu mendapat pembelajaran pendekatan metaphorical thinking dengan berbantuan software Geogebra dan kelas yang lain mendapat pembelajaran biasa. Pada awal dan akhir pembelajaran kedua kelas diberi tes, sehingga desain penelitiannya adalah:
A OXO
(Ruseffendi, 2010:50)
$\mathrm{A} O \mathrm{O}$

Keterangan:

A : Pemilihan sampel secara acak berdasarkan kelas

$\mathrm{O} \quad$ : Soal pretes $=$ soal postes

$\mathrm{X}$ : Pembelajaran menggunakan pendekatan metaphorical thinking berbantuan software Geogebra.

Pada pelaksanaannya, peneliti terlibat langsung dalam mengumpulkan, mengolah, menganalisis, serta menarik suatu kesimpulan dari data yang diperoleh. Dalam penelitian ini, sebelumnya peneliti memberikan pretes, lalu sebelum memberikan tes akhir peneliti mengajarkan materi dengan menggunakan model pembelajaran metaphorical thinking berbantuan software Geogebra pada kelas eksperimen. Pada tahap akhir peneliti memberikan soal postes pada kelas eksperimen dan kelas kontrol. 
Populasi dalam penelitian ini adalah seluruh siswa SMP di Kabupaten Bandung Barat. Sekolah yang terpilih secara acak adalah SMP Krida Utama Padalarang. Sedangkan untuk sampel diambil sebanyak dua kelas secara acak kemudian dari kedua kelas tersebut diacak kembali sehingga didapat satu kelas bertindak sebagai kelas eksperimen dan satu kelas bertindak sebagai kelas kontrol. Dalam penelitian ini terpilih secara acak kelas VIII-D sebagai kelas eksperimen yang memperoleh pembelajaran menggunakan pendekatan metaphorical thinking dengan berbantuan software Geogebra dan kelas VIII-C sebagai kelas kontrol memperoleh pembelajaran biasa.

Instrumen yang digunakan untuk mengetahui kemampuan koneksi matematis siswa SMP adalah melalui 8 soal tes, dengan tipe tes uraian. Dipilih tipe tes uraian karena hanya siswa yang telah menguasai materi dengan baik yang dapat memberikan jawaban dengan benar, selain itu melalui tipe tes uraian dapat diketahui sejauh mana pemahaman serta bagaimana bentuk pemecahan masalah siswa dalam menyelesaikan tes yang diberikan. Soal-soal yang diberikan untuk pretes dan postes sama.

Instrumen tes, merupakan instrumen yang dikembangkan sendiri oleh peneliti sesuai dengan materi yang disampaikan dan kemampuan umum siswa sehingga diharapkan instrumen yang dibuat oleh peneliti memiliki tingkat validitas yang baik. Sebelum instrumen diberikan kepada siswa kelas sampel, terlebih dahulu instrumen tersebut dikomunikasikan dengan dosen pembimbing mengenai tingkat keefektivitasan soal sesuai dengan materi yang telah disampaikan pada kelas sampel. Setelah disetujui oleh dosen pembimbing, soal-soal diuji cobakan kepada kelas sampel.

Sebelum menguji validitas, reliabiltas, daya pembeda, dan tingkat kesukaran, instrumen perlu dinilai dengan pedoman sesuai dengan kemampuan pemahaman matematik. Adapun pedoman pemberian skor pada tes bentuk uraian yang digunakan dalam penelitian ini adalah Quasar General Rubric yang dinyatakan Lane (Tusadiah, 2012:39) yang disajikan pada tabel 1.

Tabel 1. Pedoman Pemberian Skor Pada Tes Kemampuan Koneksi Matematik

\begin{tabular}{lc}
\hline \multicolumn{3}{l}{ Kriteria jawaban dan alasan } & Skor \\
\hline Tidak ada jawaban / tidak memahami masalah & 0 \\
\hline $\begin{array}{l}\text { Memahami sebagian konsep dan proses matematis soal, menggunakan alat dan } \\
\text { strategi penyelesaian yang tidak tepat dan melakukan banyak kesalahan } \\
\text { perhitungan. }\end{array}$ & 1 \\
\hline $\begin{array}{l}\text { Hampir memahami konsep dan proses matematis soal, mengidentifikasi unsur - } \\
\text { unsur penting, namun banyak ide - ide yang keliru, melakukan beberapa }\end{array}$ & 2 \\
kesalahan perhitungan. & 3 \\
\hline $\begin{array}{l}\text { Pemahaman yang baik terhadap konsep dan proses matematis soal, menggunakan } \\
\text { istilah dan notasi yang hampir benar, melakukan algoritma secara lengkap dan } \\
\text { secara umum perhitungan benar, tetapi masih terdapat kesalahan }\end{array}$ & 3 \\
\hline $\begin{array}{l}\text { Menunjukkan pemahaman terhadap konsep dan proses matematis soal, } \\
\text { menggunakan istilah dan notasi yang tepat, melaksanakan algoritma secara benar } \\
\text { dan lengkap. }\end{array}$ & 4 \\
\hline
\end{tabular}

Agar memiliki validitas isi maka soal-soal tersebut dikonsultasikan terlebih dahulu dengan dosen pembimbing. Setelah itu agar memiliki validitas empiris soal-soal tersebut diujicobakan. Kemudian dihitung validitas, reliabilitas, daya pembeda, dan indeks kesukaran.

Pada Tabel 2 di atas, terlihat bahwa rekapitulasi dari delapan butir soal yang disajikan memiliki nilai yang berbeda-beda baik dari validitas, reliabilitas, daya beda, dan indeks kesukarannya. Dari semua soal yang ada, hanya lima soal saja yang digunakan yaitu soal nomor 1 , $2,5,6,8$. 
Tabel 2. Rekapitulasi Hasil Uji Coba Instrumen

\begin{tabular}{|c|c|c|c|c|c|c|c|c|c|}
\hline \multirow{2}{*}{$\begin{array}{l}\text { No. } \\
\text { Soal }\end{array}$} & \multicolumn{2}{|c|}{ Validitas } & \multicolumn{2}{|c|}{ Reliabilitas } & \multicolumn{2}{|c|}{ Daya Pembeda } & \multicolumn{2}{|c|}{$\begin{array}{c}\text { Indeks } \\
\text { Kesukaran }\end{array}$} & \multirow{2}{*}{$\begin{array}{c}\text { Ketera- } \\
\text { ngan }\end{array}$} \\
\hline & $\mathbf{r}$ & $\begin{array}{l}\text { Inter- } \\
\text { pretasi }\end{array}$ & $\mathbf{r}_{\mathbf{p}}$ & $\begin{array}{l}\text { Inter- } \\
\text { pretasi }\end{array}$ & DP & $\begin{array}{l}\text { Inter- } \\
\text { pretasi }\end{array}$ & IK & $\begin{array}{l}\text { Inter- } \\
\text { pretasi }\end{array}$ & \\
\hline 1 & 0,77 & Tinggi & & & 0,66 & Baik & 0,67 & Mudah & Dipakai \\
\hline 2 & 0,67 & Tinggi & & & 0,41 & Baik & 0,58 & Sedang & Dipakai \\
\hline 3 & 0,72 & Sedang & & & 0,44 & Baik & 0,38 & Sukar & $\begin{array}{l}\text { Tidak } \\
\text { Dipakai }\end{array}$ \\
\hline 4 & 0,80 & Tinggi & 0,84 & Tinggi & 0,69 & Baik & 0,75 & Mudah & $\begin{array}{l}\text { Tidak } \\
\text { Dipakai }\end{array}$ \\
\hline 5 & 0,59 & Sedang & & & 0,47 & Baik & 0,55 & Sedang & Dipakai \\
\hline 6 & 0,61 & Sedang & & & 0,40 & Baik & 0,39 & Sukar & Dipakai \\
\hline 7 & 0,53 & Sedang & & & 0,31 & Cukup & 0,19 & $\begin{array}{l}\text { Sangat } \\
\text { Sukar }\end{array}$ & $\begin{array}{l}\text { Tidak } \\
\text { Dipakai }\end{array}$ \\
\hline 8 & 0,77 & Tinggi & & & 0,53 & Baik & 0,58 & Sedang & Dipakai \\
\hline
\end{tabular}

\section{HASIL DAN PEMBAHASAN}

Data statistik deskriptif siswa, kelas yang pembelajarannya menggunakan pendekatan metaphorical thinking berbantuan software Geogebra sebagai kelas eksperimen dengan kelas yang pembelajarannya menggunakan cara biasa sebagai kelas kontrol disajikan pada Tabel 3 dibawah ini:

Tabel 3. Data Deskriptif Kelas Eksperimen dan Kelas Kontrol Kemampuan Koneksi Matematik

\begin{tabular}{|c|c|c|c|c|c|c|c|}
\hline \multirow{2}{*}{ Variabel } & \multirow{2}{*}{$\begin{array}{c}\text { Data } \\
\text { Statistik }\end{array}$} & \multicolumn{4}{|c|}{ Kelas Eksperimen } & \multicolumn{2}{|c|}{ Kelas Kontrol } \\
\hline & & Pretes & Postes & Gain & Pretes & Postes & Gain \\
\hline \multirow{4}{*}{$\begin{array}{c}\text { Kemampuan } \\
\text { Koneksi } \\
\text { Matematik }\end{array}$} & $\mathrm{N}$ & & 41 & & & 40 & \\
\hline & Rata-Rata & 4,00 & 12,195 & 0,512 & 4,10 & 10,700 & 0,410 \\
\hline & Standar & 109 & 1.913 & 0.120 & 1,194 & 1.977 & 0.138 \\
\hline & $\begin{array}{c}\text { Deviasi } \\
\text { SMI }\end{array}$ & \multicolumn{6}{|c|}{20} \\
\hline
\end{tabular}

Tabel 3 menunjukan nilai kelas eksperimen lebih besar dibanding dengan kelas kontrol, namun hal tersebut belum mampu menjawab hipotesis, maka untuk menjawab hipotesis dilakukan uji prasyarat sebagai berikut:

Tabel 4. Uji Normalitas Pretes Kemampuan Koneksi Matematik

\begin{tabular}{ccccc}
\hline \multirow{2}{*}{ Kelas } & \multicolumn{3}{c}{ Kolmogorov-Smirnov $^{\mathbf{a}}$} \\
\cline { 3 - 5 } & & Statistic & Df & Sig. \\
\hline Pretest & Eksperimen & .232 & 41 & .000 \\
& Kontrol & .217 & 40 & .000 \\
\hline
\end{tabular}

Berdasarkan pada Tabel 4. terlihat bahwa signifikan pada kelas eksperimen 0,000 dan kelas kontrol 0,000. Nilai kedua kelas tersebut memenuhi kriteria pengujian uji normalitas data yaitu sig. $\leq 0,05$ maka sampel tidak berdistribusi normal. Karena data tidak berdistribusi normal, maka akan dilanjutkan dengan uji nonparametrik Mann Whitney. 
Tabel 5. Uji Signifikan Mann Whitney Pretes Kemampuan Koneksi Matematik

\begin{tabular}{cc}
\hline & Pretest \\
\hline Mann-Whitney U & 743.000 \\
Wilcoxon W & 1604.000 \\
Z & -.759 \\
Asymp. Sig. (2-tailed) & .448 \\
\hline
\end{tabular}

Berdasarkan Tabel 5. terlihat bahwa pada tabel Sig (2-tailed) sebesar 0,448. Nilai tersebut memenuhi kriteria pengujian yaitu sig. $>0,05$ maka $\mathrm{H}_{0}$ diterima. Hal ini menunjukan tidak terdapat perbedaan secara signifikan kemampuan awal koneksi matematik antara kelas yang mendapat pembelajaran dengan pendekatan metaphorical thinking berbantuan software Geogebra dengan kelas yang mendapatkan pembelajaran biasa.

Tabel 6. Uji Normalitas Postes Kemampuan Koneksi Matematik

\begin{tabular}{llrrr}
\hline \multirow{2}{*}{ Kelas } & \multicolumn{3}{c}{ Kolmogorov-Smirnov $^{\mathbf{a}}$} \\
\cline { 3 - 5 } & & Statistic & \multicolumn{1}{c}{ Df } & \multicolumn{1}{c}{ Sig. } \\
\hline Postes & Eksperimen & .224 & 41 & .000 \\
& Kontrol & .215 & 40 & .000 \\
\hline
\end{tabular}

Berdasarkan pada Tabel 6, terlihat bahwa signifikan pada kelas eksperimen dan kelas kontrol 0,00. Nilai dari kedua kelas tersebut memenuhi kriteria pengujian uji normalitas data yaitu sig. $\leq 0,05$ maka sampel tidak berdistribusi normal. Karena data tidak berdistribusi normal, maka akan dilanjutkan dengan uji nonparametrik Mann-Whitney.

Tabel 7. Uji Signifikan Mann Whitney Postes Kemampuan Koneksi Matematik

\begin{tabular}{cc}
\hline & Postes \\
\hline Mann-Whitney U & 438.000 \\
Wilcoxon W & 1258.000 \\
Z & -3.690 \\
Asymp. Sig. (2-tailed) & .000
\end{tabular}

Berdasarkan Tabel 7, terlihat bahwa nilai Sig (2-tailed) sebesar 0,000 Karena penelitian yang dilakukan untuk menelaah pencapaian maka yang digunakan Sig. (1-tailed). Menurut Sugilar (2013:165), “ $\frac{1}{2}$ sig. $(2$-tailed $)=$ sig. $(1$-tailed $)$ ”. Maka $\frac{1}{2} 0,000=0,000$. Nilai tersebut memenuhi kriteria pengujian yaitu sig. $\leq 0,05$ maka $\mathrm{H}_{\mathrm{a}}$ diterima. Hal ini menunjukan kemampuan koneksi matematik siswa SMP yang pembelajarannya menggunakan pendekatan metaphorical thinking dengan berbantuan software Geogebra lebih baik dari siswa yang menggunakan pembelajaran biasa.

Tabel 8. Uji Normalitas Gain Kemampuan Koneksi Matematik

\begin{tabular}{llccc}
\hline \multirow{2}{*}{ Kelas } & \multicolumn{3}{c}{ Kolmogorov-Smirnov ${ }^{\text {a }}$} \\
\cline { 3 - 5 } & Statistic & Df & Sig. \\
\hline Gain & Eksperimen & .199 & 41 & .001 \\
& Kontrol & .112 & 40 & $.200^{*}$ \\
\hline
\end{tabular}

Berdasarkan pada Tabel 8, terlihat bahwa signifikan pada kelas eksperimen 0,001 dan kelas kontrol $0,200 *$. Nilai dari kelas kontrol tersebut tidak memenuhi kriteria pengujian uji normalitas data yaitu sig. $\leq 0,05$ maka sampel tidak berdistribusi normal. Karena data tidak berdistribusi normal, maka akan dilanjutkan dengan uji nonparametrik Mann-Whitney. 
Tabel 9. Uji Signifikan Gain Kemampuan Koneksi Matematik

\begin{tabular}{cc}
\hline & Gain \\
\hline Mann-Whitney U & 436.000 \\
Wilcoxon W & 1256.000 \\
Z & -3.638 \\
Asymp. Sig. (2-tailed) & .000 \\
\hline
\end{tabular}

Berdasarkan Tabel 9, terlihat bahwa nilai Sig (2-tailed) sebesar 0,000. Karena penelitian yang dilakukan untuk menelaah peningkatan maka yang digunakan Sig. (1-tailed). Menurut Sugilar (2013:165), “ $\frac{1}{2}$ sig. $(2$-tailed $)=$ sig. $(1$-tailed $)$ ". Maka $\frac{1}{2} 0,000=0,000$. Nilai tersebut memenuhi kriteria pengujian yaitu sig. $\leq 0,05$ maka $\mathrm{H}_{\mathrm{a}}$ diterima. Hal ini menunjukan peningkatan kemampuan koneksi matematik siswa SMP yang pembelajarannya menggunakan pendekatan metaphorical thinking dengan berbantuan software Geogebra lebih baik dari siswa yang menggunakan pembelajaran biasa.

Adapun tahapan-tahapan pembelajaran dengan menggunakan pendekatan metaphorical thinking berbantuan software Geogebra diuraikan sebagai berikut:

a. Grounding methapors

Kegiatan ini merupakan dasar untuk memahami ide-ide matematika yang dihubungkan dengan pengalaman sehari-hari. Pada tahap ini guru memberikan contoh terlebih dahulu, lalu kemudian mendorong siswa untuk menyebutkan contoh lainnya. Ilustrasi kegiatan ini dapat dilihat empat tahap yaitu tahap connection, siswa secara berkelompok menghubungkan konsep yang sedang dipelajari dengan benda-benda nyata disekitar mereka. Tahap discovery, siswa mengalami proses penemuan suatu konsep yang berasal dari pemanfaatan pengetahuan tentang benda-benda nyata di sekitar siswa. Pada tahap invention, siswa telah menemukan konsep yang sedang dipelajari. Invention ini merupakan tahap tindak lanjut setelah discovery. Tahap application ini siswa membuat metafora dari konsep yang sedang mereka pelajari. Tahap ini dibutuhkan kreatifitas dari siswa dalam mencari metafora yang sesuai dengan konsep yang sedang dipelajari.

b. Linking methapors

Kegiatan ini membangun keterkaitan antara dua hal yaitu memilih, menegaskan, memberi kebebasan, dan mengorganisasikan karakteristik dari topik utama dengan didukung oleh topik tambahan dalam bentuk pernyataan-pernyataan metaforik. Pada tahap ini guru mengarahkan siswa untuk menghubungkan contoh yang ada pada kehidupan nyata dengan konsep yang sedang dipelajari. Disini siswa memilih beberapa obyek benda dengan diskusi kelompok dan disepakati oleh seluruh anggota kelompok.

Dalam memilih beberapa obyek, setiap anggota kelompok diberi kebebasan dalam berpendapat dan di perbolehkan mengkonsultasikannya kepada guru. Setelah menemukan beberapa obyek dilanjutkan dengan mengkelompokan obyek tersebut yang sesuai dengan konsep materi yang akan dipelajari, contoh pengelompokan obyek untuk memahami konsep rusuk. Siswa mengemukakan hasil metafora yang sesuai konsep yang dipelajari. Ilustrasi kegiatan dapat dilihat empat tahap yaitu, tahap connection ini siswa secara berkelompok menghubungkan konsep yang sedang dipelajari dengan benda-benda nyata disekitar mereka. Tahap discovery, siswa mengalami proses penemuan suatu konsep yang berasal dari pemanfaatan pengetahuan tentang benda-benda nyata di sekitar siswa. Tahap invention ini siswa telah menemukan konsep yang sedang dipelajari. Invention ini merupakan tahap tindak lanjut setelah discovery. Tahap application, siswa membuat metafora dari konsep yang sedang mereka pelajari. Pada tahap ini dibutuhkan kreatifitas dari siswa dalam mencari metafora yang sesuai dengan konsep yang sedang dipelajari.

\section{c. Redefinitional methapors}

Kegiatan ini mendefinisikan kembali metafor-metafor tersebut dan memilih yang paling cocok dengan topik yang akan diajarkan. Pada tahap ini guru memilih kelompok secara acak untuk mempresentasikan hasil diskusi kelompok. Kegiatan ini bertujuan untuk mengetahui sejauh mana siswa dapat mendefinisikan metaphor pada materi yang sedang dipelajari. Ilustrasi kegiatan dapat dilihat empat tahap yaitu, tahap connection, siswa secara berkelompok menghubungkan konsep yang sedang dipelajari dengan benda-benda nyata disekitar mereka. Tahap discovery, siswa 
mengalami proses penemuan suatu konsep yang berasal dari pemanfaatan pengetahuan tentang benda-benda nyata di sekitar siswa. Tahap invention, ini siswa telah menemukan konsep yang sedang dipelajari. Invention ini merupakan tahap tindak lanjut setelah discovery. Tahap application, siswa membuat metafora dari konsep yang sedang mereka pelajari. Pada tahap ini dibutuhkan kreatifitas dari siswa dalam mencari metafora yang sesuai dengan konsep yang sedang dipelajari.

\section{SIMPULAN}

Berdasarkan hasil analisis data dan pembahasan hasil penelitian mengenai penerapan pendekatan metaphorical thinking berbantuan software Geogebra untuk meningkatkan kemampuan koneksi matematik siswa SMP dapat ditarik kesimpulan bahwa pencapaian kemampuan koneksi matematik siswa SMP yang menggunakan pendekatan metaphorical thinking berbantuan software Geogebra lebih baik daripada yang menggunakan pembelajaran biasa. Dan peningkatan kemampuan koneksi matematik siswa SMP yang menggunakan pendekatan metaphorical thinking berbantuan software Geogebra lebih baik daripada yang menggunakan pembelajaran biasa.

\section{DAFTAR PUSTAKA}

Ace, S. (2007). Pemanfaatan ICT dalam Pembelajaran. Jurnal Pendidikan Terbuka dan Jarak Jauh, 8(1), 83-98.

Afrilianto. (2012). Peningkatan Pemahaman Konsep dan Kompetensi Strategis Matematis Siswa SMP dengan Pendekatan Metaphorical Thinking. Jurnal Ilmiah Program Studi Matematika STKIP Siliwangi Bandung, 1(2), 192-202.

Anggun Badu Kusuma, Astri Utami. (2017). Penggunaan Program Geogebra Dan Casyopee Dalam Pembelajaran Geometri Ditinjau Dari Motivasi Belajar Siswa Jurnal Mercumatika : Jurnal Penelitian Matematika dan Pendidikan Matematika FKIP Universitas Mercu Buana Yogyakarta,1(2),119-131, https://doi.org/10.26486/mercumatika.v1i2.259

Anita, I. W. (2014). Pengaruh Kecemasan Matematika (Mathematics Anxiety) terhadap Kemampuan Koneksi Matematis Siswa SMP. Infinity, 3(1), 125-132.

Bernard, M. (2015). Meningkatkan Kemampuan Komunikasi dan Penalaran serta Disposisi Matematik Siswa SMK dengan Pendekatan Kontekstual melalui Game Aobe Flash cs 4.0.Infinity Journal, 4(2), 197-222.

Chotimah, S., Bernard, M., \& Wulandari, S. M. (2018, January). Contextual Approach Using VBA Learning Media to Improve Students' Mathematical Displacement and Disposition Ability. In Journal of Physics: Conference Series (Vol. 948, No. 1, p. 012025). IOP Publishing.

Danaryanti, A. dan Dara, T. (2016). Penerapan Model Problem Prompting Learning untuk Meningkatkan Kemampuan Koneksi Matematis Siswa SMP. EDU-MAT Jurnal Pendidikan Matematika, 4, 8-14.

Fazar, I. (2015). Pemanfaatan Aplikasi Geogebra dalam Kegiatan Pembelajaran Matematika di Sekolah Menengah Atas. Prosiding Seminar Nasional Pendidikan Matematika, 31-37.

Gurria, A. (2012). Results: What Students Know and Can do Student Performance in Mathematics, Reading and Science. In US:OECD.

Kementrian Pendidikan Nasional. (2006). Standar isi untuk Satuan Pendidikan Dasar dan Menengah Standar Kompetensi dan Kompetensi Dasar SMP/MT. Jakarta: Badan Standar Nasional Pendidikan.

Rismaratri, D., \& Nuryadi, N. (2018). Pengaruh Model Pembelajaran Quantum Dengan Pendekatan Realistic Mathematic Education (RME) Terhadap Kemampuan Berfikir Kreatif Dan Motivasi Belajar Matematika. Jurnal Edukasi Matematika dan Sains, 5(2), 70-76.

Rohati. (2015). Pengembangan Perangkat Pembelajaran Berbasis Pendekatan Realistic Mathematics Education (RME) pada Materi Volume Bangun Ruang Sisi Datar yang Mendukung Kemampuan Komunikasi Matematika Siswa di SMP. Jurnal Edumatica, 5(2), 27-36. 
Ruseffendi, E. T. (2010). Dasar-Dasar Penelitian Pendidikan dan Bidang Non-Eksakta Lainnya. Bandung: Tarsito.

Saminanto, K. (2015). Analysis of Mathematical Connection Ability in Linear Equation with One Variable Based on Connectivity Theory. International Journal of Education and Research, 3(4), 259-270.

Senjayawati, E., \& Bernard, M. (2018). Penerapan Model Search - Solve - Create - Share untuk Mengembangkan Kemampuan Penalaran Berbantuan Software Geogebra 4.4, 5(1), 66-78.

Sugilar, H. (2013). Meningkatkan Kemampuan Berpikir Kreatif dan Disposisi Matematik Siswa Madrasah Tsanawiyah melalui Pembelajaran Generatif. Infinity Journal, 2(2), 156-168.

Sunito, I. et al. (2013). Methaporming (Beberapa Strategi Berpikir Kreatif). Jakarta: PT. Indeks.

Tusadiah, H. (2012). Meningkatkan Kemampuan Koneksi dan Representasi Matematis Siswa SMA melalui Pembelajaran Berbasis Mind Mapping. Tesis, tidak dipublikasikan. Pascasarjana UPI Bandung. 